\title{
Phosphine NMR challenge
}

\author{
Andryj M. Borys ${ }^{1}$ \\ (C) Springer-Verlag GmbH Germany, part of Springer Nature 2020
}

We would like to invite you to participate in the Analytical Challenge, a series of puzzles to entertain and challenge our readers. This special feature of "Analytical and Bioanalytical Chemistry" has established itself as a truly unique quiz series, with a new scientific puzzle published every three months. Readers can access the complete collection of published problems with their solutions on the $A B C$ homepage at http://www.springer.com/abc. Test your knowledge and tease your wits in diverse areas of analytical and bioanalytical chemistry by viewing this collection.

In the present challenge, NMR spectra is the topic. And please note that there is a prize to be won (a Springer book of your choice up to a value of $€ 100$ ). Please read on...

\section{Meet the challenge}

Different isotopologues of a molecule can display small changes in chemical shift observed in the NMR spectrum [1]. The magnitude of the isotope shift is affected by a number of factors including the relative change in mass of the atom or the number of bonds between the exchanged and observed nuclei. Primary isotope shifts relate to the changes in chemical shift when the isotope

Andryj M. Borys

andryjmborys@gmail.com

1 Department of Chemistry and Biochemistry, University of Bern, Freiestrasse 3, 3012 Bern, Switzerland of the observed nucleus is changed; for example the ${ }^{1} \mathrm{H}$ and ${ }^{2} \mathrm{H}$ chemical shifts in $\mathrm{CHCl}_{3}$ and $\mathrm{CDCl}_{3}$. In addition, secondary isotope shifts can occur when the isotope of neighbouring atoms is changed, for example when ${ }^{1} \mathrm{H}$ atoms are replaced with ${ }^{2} \mathrm{H}$ in $\mathrm{PH}_{3}$, with ${ }^{31} \mathrm{P}$ being the observed nucleus. Indeed, changing the isotope of a neighbouring atom can have as much influence on NMR spectra as changing the structure of the molecule itself, which is exemplified with the ${ }^{31} \mathrm{P}$ NMR spectra of $\mathrm{PH}_{3}$ and $\mathrm{PD}_{3}$ (Fig. 1).

\section{The challenge}

Figure 1 shows the ${ }^{31} \mathrm{P}$ NMR spectra of natural and deuterated phosphine. Significant isotope effects are observed when comparing these two spectra.

(a) With the aid of a splitting diagram, explain the origin of the splitting patterns for both $\mathrm{PH}_{3}$ and $\mathrm{PD}_{3}$, and give the relative intensities of the signals.

(b) For a given pair of elements, the scalar coupling constant is proportional to the product of the gyromagnetic ratios of the nuclei provided all other factors remain the same. Given that the ${ }^{1} J_{\mathrm{P}-\mathrm{H}}$ coupling constant in $\mathrm{PH}_{3}$ is ${ }^{1} J_{\mathrm{P}-\mathrm{H}}=187.8 \mathrm{~Hz}$, predict the ${ }^{1} J_{\mathrm{P}-\mathrm{D}}$ coupling constant in $\mathrm{PD}_{3}$.

We invite our readers to participate in the Analytical Challenge by solving the puzzle above. Please send the 
Fig. $1{ }^{31} \mathrm{P}$ NMR spectra of natural phosphine $\left(\mathrm{PH}_{3}\right)$ and deuterated phosphine $\left(\mathrm{PD}_{3}\right)$, recorded in $\mathrm{PhCl}$

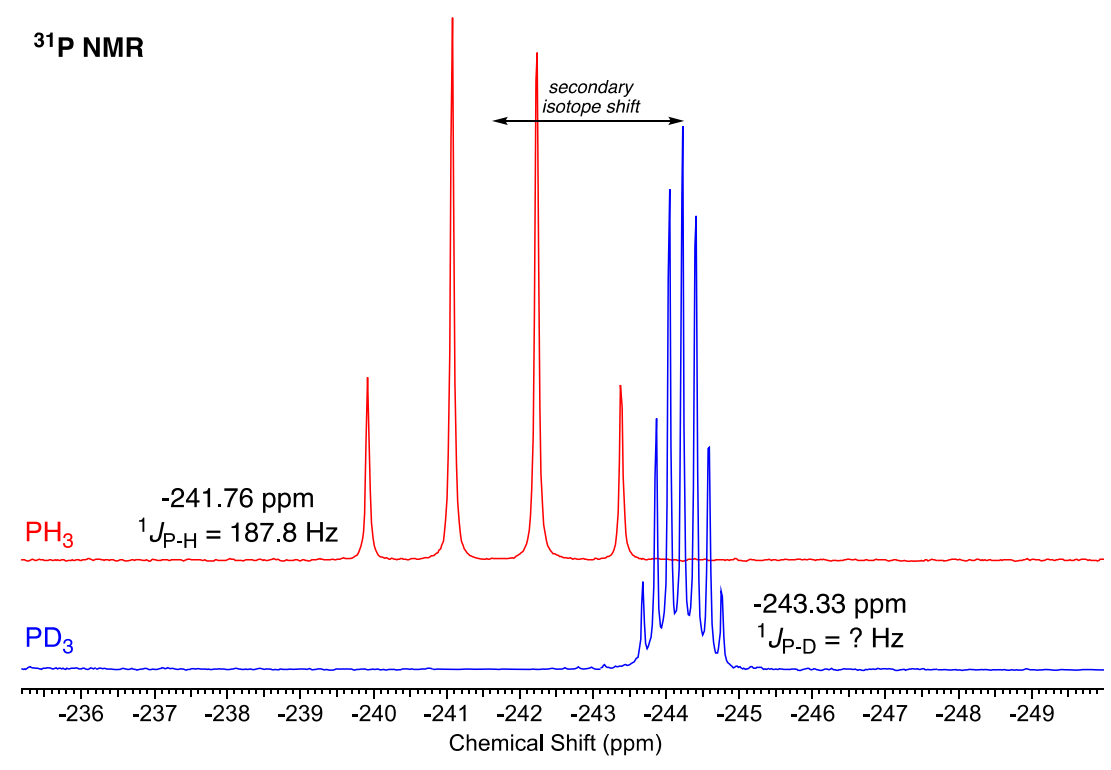

correct solution to abc-challenge@springer.com by January 1, 2021. Make sure you enter "Phosphine NMR challenge" in the subject line of your e-mail. The winner will be notified by e-mail and their name will be published on the "Analytical and Bioanalytical Chemistry" homepage at http://www.springer.com/abc and in the journal (volume 413/issue 9) where readers will find the solution and a short explanation.

The next Analytical Challenge will be published in 413/1, January 2021. If you have enjoyed solving this Analytical Challenge, you are invited to try the previous puzzles on the ABC homepage.

\section{Reference}

1. Hansen PE. Isotope effects in nuclear shielding. Prog NMR Spectrosc. 1998;20:207-55.

Publisher's note Springer Nature remains neutral with regard to jurisdictional claims in published maps and institutional affiliations. 